\title{
Sense of Humor and Emotional Intelligence as Predictors of Stress among EFL Teachers
}

\author{
Shahin Vaezi \\ Department of Foreign Languages, Iran University of Science and Technology, Iran \\ Email: sh_vaezi@iust.ac.ir \\ Nasser Fallah \\ Department of Foreign Languages, Iran University of Science and Technology, Iran \\ Email: nfallah@lang.iust.ac.ir
}

\begin{abstract}
This study investigated the association of teacher stress with sense of humor and emotional intelligence (EI) among 108 EFL teachers from 5 private language institutes in Tehran. It was also checked that whether sense of humor and EI could predict teacher stress. The participants were administered Fimian's (1984) Teacher Stress Inventory (TSI), Thorson and Powell's (1993) Multidimensional Sense of Humor Scale (MSHS), and Bar-On's (1997) EI test. A series of Pearson Product Moment Correlations and a 2-step Hierarchical Regression Analysis were run. The findings revealed that EFL teachers' sense of humor and EI were reversely correlated with their stress level. It was also found that, after accounting for the contribution of demographic variables, sense of humor and EI could collectively add to the prediction of teacher stress, however, only EI could separately predict teacher stress. Implications of the study are discussed, and suggestions for future research are made.
\end{abstract}

Index Terms - stress, sense of humor, emotional intelligence, EFL teachers

\section{INTRODUCTION AND LITERATURE REVIEW}

Since the pioneering work of Kyriacou and Sutcliffe (1978a, b, 1979), numerous studies on teacher stress have been conducted worldwide (e.g., Farber 1984, 1991; Heibert \& Farber, 1984; Kyriacou, 1980). Due to the high level of teacher attrition, teacher stress remains an important topic in educational research today (Backhirova, 2005). In recent years, it has become a global concern, considering that about as many as a third of the teachers surveyed in various studies around the world reported that they regarded teaching as highly stressful (Borg, 1990).

Kyriacou and Sutcliffe (1978a) described teacher stress as a response syndrome of negative affect (such as anger and depression), usually accompanied by physiological changes (such as increased heart rate) resulting from aspects of the teacher's job and mediated by the perception that the demands made upon the teacher constitute a threat to his or her self-esteem or well being. According to Pennicuik (2003), the less stressful a person is at work, the more likely he or she will be present and the more likely the production and performance will increase (Pennicuik, 2003). Several factors determine how stressful a job is. Psychological demands placed on the individual and the ability to manage certain aspects of his or her job are identified by Hanson and Sullivan (2003) as important factors.

In identifying the most common sources of teacher stress, different investigators in different settings have come up with a diversity of stressors that include students' misbehaviors and discipline problems, students' poor motivation for work, heavy workload and time pressure, role conflict and role ambiguity, conflicting staff relationships in school management and administration, and pressure and criticisms from parents and the wider community (see Dunham, 1992; Travers \& Cooper, 1996). Pithers and Soden (1998) assessed levels of strain, organizational roles and stress in 322 Australian and Scottish vocational lecturers. Strain was found to be average in both national groups, but there were high levels of stress with role overload emerging as the major cause. Lewis (1999) examined teachers' estimations of stress arising from being unable to discipline pupils in the way they would prefer. Overall, maintaining discipline emerged as a stressor, with those worst affected being teachers who placed particular emphasis on pupil empowerment. Morton et al (1997) conducted a study of 1000 student teachers. The results revealed that classroom management was their second greatest sources of anxiety, the greatest being evaluation apprehension. Of all the stressors reported, classroom management anxiety was the only one that did not decline following teaching practice.

Jepson and Forrest (2006) suggested that teacher experience with stress differs as teaching experience increases. Beginning teachers often suffer from stress early because they are often given classroom assignments and students that are identified as difficult (Bobek, 2002). Many teachers enter into the profession with passion and energy, but soon run out because of stress. According to Intrator (2006), there are multiple evokers of intense emotions;

1. The public scrutiny of standing in front of a classroom the fear of not being liked or respected by students;

2. The vulnerability that comes with awareness of how students, administrators, and cooperating teachers routinely judge your performance; 
3. The anxiety that comes when you are teaching a subject where your own understanding is incomplete; or

4. The discomfort that comes from having to make rapid-fire and uncertain decisions, whether in disciplining a student, correcting a student, asking a question, or adapting a lesson on the fly. (p. 235)

Just the same, veteran teachers also experience stress because of the changing roles, extension of additional duties and the new direction of education.

Moreover, the amount and degree of stress a teacher experiences may be related to his negative self-perception, negative life experiences, low morale, and the struggle to maintain personal values and standards in the classroom (Worrall \& May, 1989). Interestingly, Kyriacou and Sutcliff (1978a) pointed out that stress reactions would vary among individuals, even when the objective external conditions are the same. Specifically, some teachers might develop psychological symptoms of varying severity, ranging from mild frustration, anxiety, and irritability to emotional exhaustion as well as psychosomatic and depressive symptoms (e.g., Dunham, 1992; Farber, 1984; Kyriacou \& Pratt, 1985).

Therefore, it seems natural that one should raise the question as to why some teachers succeed in surmounting high levels of occupational stress, in continuously enhancing students' achievements, and in setting and pursuing high goals for themselves, while others cannot meet expectations imposed on them and tend to collapse under the burden of everyday stress. The reason may lie in teachers' sense of humor as a coping mechanism and their emotional intelligence as a coping resource which includes a range of non-cognitive capabilities, competencies, and skills that have an impact on one's ability to succeed in coping with environmental demands and pressures (Bar-On, Brown, Kirkcaldy and Thome, 2000).

In this connection, humor has been viewed by several theorists as one of the highest adaptive mechanisms of coping (Lefcourt, 2001). It is often difficult for an individual to take an objective stance in a stressful situation. However, humor, as a coping mechanism, offers one the opportunity to step back from the immediate stress of a situation and view it from a distance (Morreall, 1983). Martin and Lefcourt (1984) found that when individuals use humor to face anxiety, they are able to find multiple ways of interpreting their situation.

There is also a considerable amount of research that has acknowledged the association of pedagogically appropriate humor with: (a) positive teacher evaluations, (b) greater student enjoyment of the subject, and (c) greater student retention (Martin, 2007). Humor has also been shown to be appropriate for students at all levels and remains to be a powerful, positive, effective instructional tool for advancing learning (Berk, 2002; Polio \& Humphreys, 1996). Empirical studies have concluded that students learn more from teachers who have a strong humor orientation than those with a weaker orientation (Korobkin, 1988; Martin, 2007; Torok, McMorris, \& Lin, 2004). It has also been shown that teachers who effectively use humor are able to convey course content more effectively (Downs, Javidi, \& Nussbaum, 1988). Humor in the classroom is not the answer to all classroom management issues, but it is an excellent preventive measure and can often diffuse tense situations (Loomans \& Kolberg, 1993). Humor, in fact, may be one way to decrease teacher burnout caused by unmediated stress (Abel, 2002; Kuiper \& Martin, 1998; Talbot \& Lumden, 2000).

On the other hand, Ciarrochi, Chan and Caput, (2000) posited that emotional intelligence may protect people from stress and lead to better adaptation. They opined that an objective measure of emotion management skill is associated with a tendency to maintain an experimentally induced positive mood which has obvious implication for preventing stress. Teachers who experience more positive emotions may generate more and better teaching ideas; they may also develop "broad-minded coping" skills (Frederickson, 2001, p. 223), which can help them solve more problems. Kremenitzer (2005) stated that "being able to regulate and manage emotions within the classroom is an important factor for effective and successful teaching" (p. 7). He argued that unlike other skills that a teacher has, the ability to respond to unanticipated and difficult spontaneous situations is perhaps the most challenging of all. When the time frame for reflection is short, teachers must be able to make a quick emotional adjustment even in the middle of the most negative situation.

Bar-On (2003) found that there was a moderate yet significant relationship between emotional and social intelligence and psychological health. Teachers who experience more positive emotions may generate more and better teaching ideas; they may also develop "broad-minded coping" skills (Frederickson, 2001, p. 223), which can help them solve more problems. Research studies have also demonstrated that emotional intelligence could help foster effective coping with past events and traumatic experiences (e.g., Nolen-Hoeksema, McBride, \& Larson, 1997; Pennebaker, 1997), with anticipation of desired goals in the future (e.g., Taylor, Pham, Rivkin, \& Armor, 1998), and with current events and chronic stress (e.g., Folkman \& Moskowitz, 2000).

Further, some empirical studies have been conducted to test the relationship between EI and stress among people from different walks of life. For example, Nikolaou and Tsaousis (2002) explored the relationship between occupational stress and emotional intelligence. They found a negative correlation between emotional intelligence and stress at work, indicating that workers who had higher overall emotional intelligence suffered less stress related to the occupational environment. Slaski and Cartwright (2002) investigated the relationship between a measure of emotional intelligence, subjective stress, distress, health, morale, quality of working life, and management performance. Their findings indicated a significant link between emotional intelligence and health and performance. These findings were encouraging in that emotional intelligence may play an important role in moderating the stress process and increasing individual resistance (Slaski \& Cartwright, 2002). 
However, there is a glaring lacuna in the existent literature on the association of teacher stress with EI and sense of humor in the context of teaching a foreign language with its emotionally challenging nature, high levels of affective involvement, complexity and constant interaction (Vaezi \& Fallah, 2011a, b). Therefore, the purpose of the present study is to extend current research pertaining to teacher stress. Specifically, the relationship between EFL teachers' stress, their EI and sense of humor will be examined. As such, this study intends to answer the following two research questions:

1. Are there significant relationships between stress, EI and sense of humor among EFL teachers?

2. Can EI and sense of humor add to the prediction of stress among EFL teachers after accounting for the contribution of demographic variables?

\section{Methodology}

\section{A. Participants and Procedures}

The participants in this study consisted of 108 EFL teachers ( 52 females and 56 males) aged between 20 and 47 years old $(M=28.43, S D=5.12)$ with a range of between 1 and 19 years of teaching experience $(M=6.52, S D=3.93)$. Fifty five teachers $(50.9 \%)$ were single and $53(49.1 \%)$ were married. They were selected from 5 private language institutes in Tehran.

To receive reliable data, the researchers explained the purpose of the study to the participants and informed them about the approximate time needed to complete the questionnaires (approximately 40 minutes). Further, all teachers were assured that their participation would be anonymous and voluntary. It was also explained that the results would consist of group data and that individual participants and institutes would not be identified. This information was presented in an informed consent form that was handed out with the survey packet. The completion of the survey packet indicated implied consent and thus no signed consent form was returned. Participants were encouraged to keep the informed consent page for their records. Teachers were encouraged to contact the investigators if any questions or concerns arose as a result of their participation in the study. The participants took the questionnaires home, filled them in and submitted it to the researchers within a week.

Finally, in order to answer the research inquiry, the responses obtained from the questionnaires were tabulated and analyzed.

\section{B. Instruments}

An anonymous self-report questionnaire, comprising 3 scales and a subject fact form, served as the research tool in this study. The 3 scales measured teachers' EI and sense of humor and stress. The fact form enquired about participants' demographic information including age, gender, marital status and years of teaching experience.

\section{Teacher Stress Inventory (TSI)}

Teacher stress was measured using the Teacher Stress Inventory (TSI). The TSI was developed by Fimian (1984) to measure teachers' perception of stress as it relates to their occupation. The TSI includes 49 items on a 5 point Likert scale, and it covers 10 factors which are broken down into stress factors and stress manifestations. The five stress source factors are Time Management, Work-Related Stressors, Professional Distress, Discipline and Motivation, and Professional Investment. The five stress manifestations factors are Emotional Manifestations, Fatigue Manifestations, Cardiovascular Manifestations, Gastronomic Manifestations, and Behavioral Manifestations. In this study, the reliability estimate of the scale was $\alpha=0.89$.

\section{Sense of Humor Scale}

Thorson and Powell's (1993) Multidimensional Sense of Humor Scale (MSHS) was utilized to measure EFL teachers' sense of humor. The MSHS is an auto-report measure of overall sense of humor and is composed of 24 items assessing humor on four dimensions. These four dimensions include: (a) the creation or production of humor, (b) humor used as a coping mechanism, (c) humor used socially, and (d) humor appreciation. Respondents indicate their agreement with the statements by selecting responses from a five-point Likert scale with responses ranging from 1(Strongly Disagree) to 5 (Strongly Agree). In the current study the reliability estimate of the scale was $\alpha=0.91$.

\section{EI scale}

To evaluate language teachers' EI, the researcher employed “Bar-On EI test” (Bar-On, 1997). This test employs a 5point response scale with a textual response format ranging from strongly disagree to strongly agree. It includes 5 major factors and 15 subfactors or components (discussed in the introduction section). In this study, a Persian version of the EI test with 90 items was utilized. According to Samouei (2003), the questionnaire has generally good internal consistency, test-retest reliability, and constructs validity. To analyze the questionnaire in Iran, Samouei chose a group of 500 university students (aging from 18 to 40) in Tehran and analyzed the norms of the test. As he stated, the questionnaire has generally good internal consistency, test-retest reliability, and construct validity. With the adapted version in Iran, the Cornbach's alpha coefficient was found to be 0.93 and the reliability index gained through odd-even, split-half method was [0.88].

\section{RESULTS}




\section{A. Research Question 1}

In order to investigate intercorrelation between variables a series of Pearson Product-Moment Correlation analysis was utilized. Regarding research question one, the results indicated that teacher stress was reversely correlated with both sense of humor and EI as follows: stress and sense of humor $(r=-.25, p<.01)$ and EI $(r=-.56, p<.01)($ see Table 1).

TABLE 1.

INTERCORRELATIONS BETWEEN VARIABLES $(\mathrm{N}=108)$

\begin{tabular}{|c|c|c|c|c|c|c|c|}
\hline Variables & 1 & 2 & 3 & 4 & 5 & 6 & 7 \\
\hline 1. EI & - & $.48 * *$ & $-.56^{* *}$ & $.38 * *$ & $.25^{* *}$ & $.29 * *$ & .02 \\
\hline 2. $\mathrm{SH}$ & & - & $-.25 * *$ & $.27 * *$ & .17 & .16 & .15 \\
\hline 3. TS & & & - & $-.27 * *$ & $-.32 * *$ & $-.24 * *$ & $-.22 *$ \\
\hline 4. YTE & & & & - & $.68 * *$ & $.48 * *$ & .14 \\
\hline 5. Ag & & & & & - & $.44 * *$ & $.23 *$ \\
\hline 6. MS & & & & & & - & -.01 \\
\hline 7. $\mathrm{Gn}$ & & & & & & & - \\
\hline
\end{tabular}

Note. $\mathrm{EI}=$ Emotional Intelligence, $\mathrm{SH}=$ Sense of Humor, TS = Teacher Stress, YTE = Years of Teaching Experience, Ag = Age, MS = Marital Status

\section{B. Research Question 2}

In order to find whether sense of humor and EI could predict teacher stress, a 2-step hierarchical regression analysis was run. It should be noted that prior to running the regression analysis, preliminary data screening techniques were used to check the assumptions including normality, linearity, multicollinearity, outliers and sample size. No assumptions were violated and therefore no data transformation techniques were required.

Additionally, to determine which demographic variables needed to be controlled in the regression equations, a series of correlation analyses was run to obtain the correlation between the dependent variable and the demographics. For this purpose, Gender and Marital Status were dummy coded into quantitative terms. Only variables showing significant associations (Tabachnick and Fidell, 1996) with the stress measure were included in the subsequent regression equations. It was found that all the demographics were significantly correlated with stress (see Table above). Therefore, all of them were retained.

Since no assumption was violated, no data transformation techniques were required. Then to answer the second research question as to whether sense of humor and emotional intelligence can add to the prediction of stress after accounting for demographic variables, a 2-step hierarchical regression analysis was run.

As shown in Table 2, Step 1 which included demographic variables was significantly predictive of teacher stress, accounting for $13 \%$ of the variance $\left(\mathrm{R}^{2}=.13, \mathrm{~F}[4,103]=4.08, \mathrm{p}<0.01\right)$. EI and sense of humor were added in Step two. They collectively and significantly added to the model $\left(\Delta \mathrm{R}^{2}=.25, \Delta \mathrm{F}[2,101]=21.54, \mathrm{p}<0.01\right)$, explaining an additional $25 \%$ of the variance in teachers' stress levels.

TABLE 2.

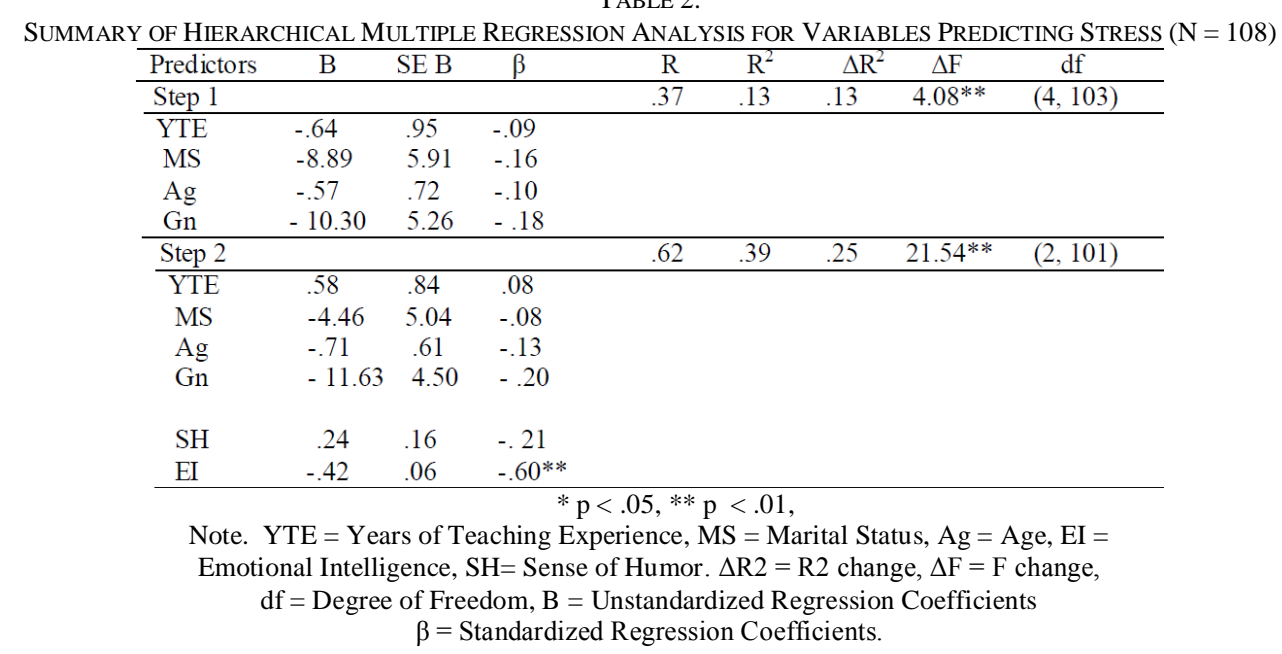

As indicated by Standardized Beta Values, EI $(\beta=.60, \mathrm{p}<.01)$ could significantly predict teacher stress. However, sense of humor $(\beta=.22, p>.05)$ could not significantly and separately predict teacher stress.

\section{DisCUSSIONS}


As stated before, the present study sought to examine the relationship between stress, EI and sense of humor among EFL teachers. In addition, the predictive strength of EI and sense of humor was tested. The size of these correlations indicates that the higher the teachers' EI, and sense of humor, the lower their stress level. The findings also showed that, after accounting for the contribution of demographic variables including teacher age, teaching experience, marital status and gender, EI and sense of humor could collectively predict stress among the teachers. However, only EI could separately have a significant predictive strength.

One plausible explanation for the EI significant potency in predicting teacher stress and their negative correlation could be that highly emotionally intelligent individuals are particularly adept at perceiving their needs, as well as the needs of others with whom they work, both which enable them to anticipate and cope with stress instead of being overwhelmed by it (Bar-On, 1997). The results are in accordance with previous theoretical and empirical studies on the role of emotional intelligence in stress, though these are noticeably slim in the foreign/second language context. According to Bar-On (1997), emotionally intelligent people "are generally optimistic, flexible, realistic, and successful at solving problems and coping with stress, without losing control" (p. 156). Those who score high on emotional intelligence skills are expected to cope more effectively with environmental demands and pressures associated with occupational stress and health outcomes than those who score low on EI (Brackett, Palomera \& Mojsa, 2010; Mendez, 2002).

A study conducted by Salovey, Bedell, Detweiler, and Mayer (1999) discovered that individuals who are able to regulate their emotional states are healthier because they "accurately perceive and appraise their emotional states, know how and when to express their feelings and can effectively regulate their mood states" (p. 161). This suggests that there is a direct connection between emotional intelligence skills and physical as well as psychological health (Tsaousis \& Nikolaou, 2005). Individuals are emotionally intelligent then they can cope better with life's challenges and control their emotions more effectively (Taylor, 2001). Harrod and Scheer (2005) also held that emotional intelligence is the driving force behind the factors that affect personal success and everyday interactions with others. The results also support Bar-On, et al., (2000), Nikolaou and Tsaousis (2002) and Slaski \& Cartwright (2002) who all found negative relationship between stress and EI among participants from different walks of life.

On the other hand, the results, indicating significant correlation between teacher sense of humor and stress, substantiate the view that humor positively affects the appraisal of stressful events and attenuates the negative affective response (Kuiper et al. 2004; Martin et al. 1993).Kuiper and Martin (1998a) suggest, individuals with a good sense of humor use more realistic processing of stressful events. Humor has been linked to several coping strategies such as distancing oneself from the stressor (Kuiper and Martin (1998b; Lefcourt, 2001), aggressive efforts toward confronting and dealing with the stress (Kuiper and Martin (1998b), and resolving the problems causing stress (McCrae and Costa 1986). Consequently, the results support the suggestion that individuals with a good sense of humor more accurately and realistically appraise the stress in their lives than those with a poor sense of humor (Kuiper and Martin 1998b; Martin, 2003). It appears that individuals with a poor sense of humor may either overestimate the appraisal of stress in their lives or perhaps are more predisposed to psychologically experience greater stress regardless of the number of stressful life events. One plausible explanation for this finding is that through sense of humor teachers can create a pleasant atmosphere in the classroom which will be undisputedly conducive to increasing interaction between teacher and learners .Wubbels et al. (1991) deemed the relationship between teacher and students the most significant aspect of classroom atmosphere. This is more evident in EFL settings, and even crucial in private institutes where group work and discussion are prevalent practices. In such a classroom, teacher's positive personality is an indispensable ingredient. Thus, the more the teacher attempts at creating an interactive supportive atmosphere, the more adept s/he will be in assuaging stress and high tensions inherent to the nature of EFL teaching especially in private language institutes which have set high pedagogical standards for teachers to meet.

\section{CONCLUSION}

The overall results of the present study lead to the conclusion that enhancing teachers' sense of humor and especially their EI might have a buffering effect on their stress level.

Foreign language teaching is a complex task that is associated with anxiety and feelings of uneasiness, frustration, self-doubt and apprehension, also teachers have to deal with students who come to class not only with diverse abilities but also with a range of emotional tendencies. Based on these findings, EI can be a potential coping resource against teacher stress. Since EI can be taught and developed (Goleman, 1995), EFL teachers should be helped in teacher preparation programs to be aware of the concept of EI and develop it in themselves, so that they can help better address stressful events in language institutes and create better educational situations for their students.

As Hawkey (2006) suggested, teacher education needs to address emotion in education in more explicit ways than is currently the case. Moreover, he points out that:

Emotionality lies at the intersection of the person and society, for all persons are jointed to their societies through the self-feelings and emotions they feel and experience on a daily basis. This is the reason the study of emotionality must occupy a central place in all the human disciplines, for to be human is to be emotional (p. 139).

Moreover, as suggested by many psychologists, humor is a set of attitudes and skills which can be learnt through practice (e.g. Fry, 1984), and everyone has the potential for a sense of humor and we are all born with the capacity to 
laugh (Fry, 1984). As a result, individual EFL teachers are advised to consciously adopt humor in their personal and teaching life. It is hoped that teachers would then keep their problems in perspective, or at least have a different focus during some of the discouraging or depressing low points. Besides, those with staff development responsibilities are suggested to encourage teachers to be more humorous and provide them with opportunities for acquiring such skill. For examples, the institute authorities should emphasize the functions of humor and introduce certain skills of being humorous in orientation programs for beginning and inexperienced teachers. The education department and teachers' union should organize workshops or in-service programs for teachers on how to keep their ever present stresses in perspective, and there the roles and functions of humor should also be introduced. A state of no stress is impossible in nature. We all have felt the tensions of stress, and we all have experienced the exhilarating feeling that follows laughter. Humor is really a healthy technique to put events and people in the proper perspective (Dardick, 1990). Thus, there is no reason to be so reluctant to incorporate some humor in our life.

The findings of the current study, however, must be treated with caution. To the researchers' best knowledge, this is the first attempt to study EFL teachers' stress, their EI and sense of humor together in an institutional context. Thus, this study should be replicated to see whether similar findings can be obtained elsewhere. Since this study was conducted only in private language institutes, further research needs to be carried out at high schools in order to compare the results.

Though considered as overall terms in the present study, sense of humor and emotional intelligence are multidimensional constructs; therefore, a promising area of research could focus on determining the specific dimensions of these two constructs which are most influential in the cognitive appraisal of stress. Finally, in addition to self-report measures, in-depth interviews, life histories, case analyses, and observational examinations are just a few examples of some other approaches that could add significant descriptions and nuances to the teacher stress database.

\section{REFERENCES}

[1] Abel, M. (2002). Humor, stress, and coping strategies. Humor, 15(4), 365-381.

[2] Bachkivora, T., (2005). Teacher stress and personal values. School Psychology International, 26 (3), 340-352.

[3] Bar-On, R. (1997). The Emotional Quotient Inventory (EQ-I): Technical Manual. Toronto: Multi-Health Systems.

[4] Bar-On, R. (2003). How important is it to educate people to be emotionally and socially intelligent, and can it be done?. Perspectives in Education, 21 (4), 3-13.

[5] Bar-On, R., Brown, J.M., Kirkcaldy, B. D. \& Thome, E.P. (2000), Emotional expression and implications for occupational stress: an application, Personality and Individual Differences, 28, 1107- 1118.

[6] Berk, R. (2002). Humor as an instructional defibrillator. Sterling, VA: Stylus Publishing.

[7] Borg, M. 1. (1990). Occupational stress in British educational settings: A review. Educational Psychology, 10, 103-126.

[8] Bobek, B. L. (2002). Teacher resiliency: A key to career longevity. The Clearing House, 75 (4), 202-205. Retrieved, from Education Periodicals database. (Document ID: 119553592).

[9] Brackett, M. A., Palomera, R., Mojsa-Kaja, J., Reyes, M. R., \& Salovey, P. (2010). Emotion-regulation ability, burnout, and job satisfaction among British secondary-school teachers. Psychology in the Schools, 47 (4), 406-417.

[10] Ciarrochi, J. Chan, A. \& Caputi, P. (2000). A critical evaluation of the emotional intelligence construct. Personality and Individual Differences, 28, 539-561.

[11] Dardick, G. (1990). Learning to laugh on the job. Principal. 69 (5), 32, 34.

[12] Downs, V., Javidi, M., \& Nussbaum, J. (1988). An analysis of teachers' verbal communication within the college classroom: Use of humor, self-disclosure, and narratives. Communication Education, 37, 127-141.

[13] Dunham, J. (1992). Stress in teaching (2nd ed.). London: Routledge.

[14] Farber, B. A. (1984). Teacher burnout: Assumptions, myths, and issues, Teachers College Record, 86, 321-338.

[15] Farber, B. A. (1991). Crisis in education: Stress and burnout in the American teacher. San Francisco: Jossey-Bass, Inc.

[16] Fimian, M. J. (1984). The development of an instrument to measure occupational stress in teachers: The Teacher Stress Inventory. Journal of Occupational Psychology, 57, 277-293.

[17] Folkman, S., \& Moskowitz, J. T. (2000). Positive affect and the other side of coping. American Psychologist, 55, $647-654$.

[18] Frederickson, B. L. (2001). The role of positive emotion in positive psychology: the broadening-and-build theory of positive emotion. American Psychology, 56, 218-226.

[19] Fry, W. (1994). The biology of humor. Humor: International Journal of Humor Research, 7 (2), 111-126.

[20] Goleman, D. (1995). Emotional Intelligence: Why It Can Matter More Than IQ. New York: Bantam Books.

[21] Hansen, J., \& Sullivan, B. (2003). Assessment of workplace stress: Occupational stress, its consequences, and common causes of teacher stress. Informational Analysis. ERIC Digest. ERIC Clearinghouse on Teaching and Teacher Education, (Eric Document reproduction Service No. ED480078). Washington, DC.

[22] Harrod, R. N., \& Sheer, D. S. (2005). An exploration of adolescence emotional intelligence in relation to demographic characteristics. Adolescence, 40 (159).

[23] Hawkey, K. (2006). Emotional intelligence and mentoring in pre-service teacher education: a literature review. Mentoring \& Tutoring, 14 (2), 137-147.

[24] Heibert, B. \& Farber, I. (1984). Teacher stress: A literature survey with a few surprises. Canadian Journal of Education, 9 (1), 14-27.

[25] Intrator, S. (2006). Beginning teachers and the emotional drama of the classroom. Journal of Teacher Education. 57 (3), $232-$ 239.

[26] Jepson, E., \& Forrest, S. (2006). Individual contributory factors in teacher stress: The roll of achievement striving and occupational commitment. British Journal of Educational Psychology, 76, 183-197. 
[27] Korobkin, D. (1988). Humor in the classroom: Considerations and strategies. College Teaching, 36, 154-158.

[28] Kremenitzer, J. P. (2005). The emotionally intelligent early childhood educator: self-reflective journaling. Early Childhood Education Journal, 33 (1), 3-9.

[29] Kuiper, N. A., Grimshaw, M., Leite, C., \& Kirsh, G. (2004). Humor is not always the best medicine: Specific components of sense of humor and psychological well-being. Humor: International Journal of Humor Research, 17, 135-168.

[30] Kuiper, N.A. , \& Martin, R. A. (1998b). Is sense of humor a positive personality characteristic? In W. Ruch (Ed.), The sense of humor: Explorations of a personality characteristic (pp.159-178).New York: Mouton de Gruyter.

[31] Kuiper, N. A. \& Martin, R. A., (1998b). Laughter and stress in daily life: Relation to positive and negative affect. Motivation and Emotion, 22 (2), 133-153.

[32] Kyriacou, C. (1980). Stress, health and schoolteachers: A comparison with other professions. Cambridge Journal of Education, 10, 154-159.

[33] Kyriacou, C., \& Pratt, J. (1985). Teacher stress and psychoneurotic symptoms. British Journal of Educational Psychology, 55, 61-64.

[34] Kyriacou, C., \& Sutcliffe, J. (1978a). A model of teacher stress. Educational Studies, 4, 1-6.

[35] Kyriacou, C., \& Sutcliffe, J. (1978b). Teacher stress: Prevalence, sources, and symptoms. British Journal of Educational Psychology, 48, 159-167.

[36] Lefcourt, H. (2001). Humor: The psychology of living buoyantly. New York: Kluwer Academic.

[37] Lewis R (1999). Teachers coping with the stress of classroom discipline. Social Psychology of Education 3, 155-171.

[38] Loomans, D., \& Kolberg, K. J. (1993). The laughing classroom: Everyone's guide to teaching with humor and play. Tiburon, CA: H. J. Kramer.

[39] Martin, R. A. (2003). Sense of humor. In S. J. Lopez \& C. R. Snyder (Eds.), Positive psychological assessment: A handbook of models and measures (pp. 313-326). Washington, DC: American Psychological Association.

[40] Martin, R. A. (2007). The psychology of humor: An integrative approach. New York: Elsevier Academic Press.

[41] Martin, R., \& Lefcourt, H. (1984). Sense of humor as a moderator of the relation between stressors and moods. Journal of Personality and Social Psychology, 47, 145-155.

[42] McCrae, R. R., \& Costa, P. T. (1986). Personality, coping, and coping effectiveness in an adult sample. Journal of Personality 54, 385-405.

[43] Mendes, J. (2002). The Relationship between emotional intelligence and occupational burnout in secondary school teachers. Dissertation Abstracts International, 63, (10), 4951A.

[44] Morton L. L., Vesco R., Williams N. H., \& Awender M. A. (1997). Student teacher anxieties related to class management, pedagogy, evaluation and staff relations. British Journal of Educational Psychology, 67, 69-89.

[45] Morreall, J. (1983). Taking laughter seriously. Albany, NY: State University of New York.

[46] Nikolaou, I. \& Tsaousis, I (2002). Emotional Intelligence in the Workplace: Exploring its effects on Occupational Stress and Organizational Commitment. International Journal of Organizational Analysis. Special Issue on Emotional Intelligence, 10, 327-342.

[47] Nolen-Hoeksema, S., McBride, A., \& Larson, J. (1997). Rumination and psychological distress among bereaved partners. Journal of Personality and Social Psychology, 72, 855-862.

[48] Pennebaker, J. W. (1997). Writing about emotional experiences as a therapeutic process. Psychological Science, 8, $162-166$.

[49] Pennicuik, S. (2003). Stop stress at work: A union guide for workers. Australian Council of Trades Union Occupational Health and Safety Unit. Retrieved from www.actu.asn.au

[50] Pithers, R. T., \& Soden R. (1998). Scottish and Australian teacher stress and strain: A comparative study. British Journal of Educational Psychology, 68, 269-279.

[51] Polio, H., \& Humphreys, W. (1996). What award-winning lecturers say about their teaching: It's all about connection. College Teaching, 44 (3), 101-106.

[52] Samouei, R. (2003). Emotional intelligence test (Bar-On's EQ-I). Tehran: Sina Research Center of Behavioral Sciences.(In Persian)

[53] Salovey, P., Bedell, B. T., Detweiler, J. B., \& Mayer, J. D. (1999). Coping intelligently: Emotional intelligence and the coping process. In C.R. Snyder (Ed.), Coping: The psychology of what works (pp. 141-164). New York: Oxford Psychology Press.

[54] Slaski, AM. and Cartwright, S. (2002). Health, performance and emotional intelligence: an exploratory study of retail managers, Stress and Health, 18 (2), 63-68.

[55] Tabachnick, B. G., \& Fidell, L. S. (1996). Using multivariate statistics (3rd edition). New York: HarperCollins.

[56] Talbot, L. A., \& Lumden, D. B. (2000). On the association between humor and burnout. Humor: International Journal of Humor Research, 13, 419-428.

[57] Taylor, G. J. (2001). Low emotional intelligence and mental illness. In J. Ciarrochi, \& J. P. Forgas (Eds), Emotional intelligence in everyday life: A scientific inquiry (pp.67-81). Philadelphia, PA: Taylor \& Francis.

[58] Taylor, S. E., Pham, L. B., Rivkin, I. D., \& Armor, D. A. (1998). Harnessing the imagination: Mental simulation, selfregulation, and coping. American Psychologist, 53, 429-439.

[59] Thorson, J., \& Powell, F. (1993a). Development and validation of a multidimensional sense of humor scale. Journal of Clinical Psychology, 49 (1), 13-23.

[60] Torok, S., McMorris, R., \& Lin, W. (2004). Is humor an appreciated teacher tool? Perceptions of professors' teaching styles and use of humor. College Teaching, 52 (1), 14-20.

[61] Travers, C. J., \& Cooper, C. L. (1996). Teachers under pressure: Stress in the teaching profession. London: Routledge.

[62] Tsaousis, I., \& Nikolaou, I. (2005). Exploring the relationship of emotional intelligence with physical and psychological functioning. Stress and Health, 21, 77-86.

[63] Vaezi, S., \& Fallah, N. (2011a). The relationship between emotional intelligence and burnout among Iranian EFL teachers. Language Teaching and Research, Issue 5 (In Press). 
[64] Vaezi, S., \& Fallah, N. (2011b). The relationship between self-efficacy and stress among Iranian EFL teachers. Language Teaching and Research, Issue 5 (In Press).

[65] Wubbels, T., Brekelmans, M., Hooymayers, H., (1991). Interpersonal teacher behaviour in the classroom. In: Faser, B.J., Walberg, H.J.(Eds.), Educational Environments: Evaluation, Antecedents and Consequences (pp. 141-160) . Pergamon Press, Oxford,

[66] Worrall, N., \& May, D. S. (1989). Towards a person-in-situation model of teacher stress. British Journal of Educational Psychology, 59, 174-86.

Shahin Vaezi has a Ph.D. in TEFL. She is an assistant professor at the Iran University of Science and Technology. Her research interests are related to teaching English to young learners and metacognition and the processes that one engages in while learning a language. As she works with E-Learning Center at the Iran University of Science and Technology, she has gained insight into teaching English in virtual classrooms. She is also an advocate of trying to reframe ELT research and practice to contextualize it within various cultural contexts. She has published and presented her ideas in various national and international conferences.

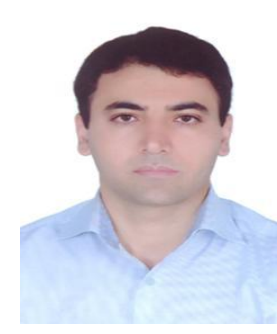

Nasser Fallah is an MA graduate of TEFL at Iran University of Science Technology. His main research interests are Reading and Vocabulary Learning Strategies, CALL, FFI and Teacher Education. He has published several papers in different international journals. 